\title{
Clinical relevancy and determinants of potential drug-drug interactions in chronic kidney disease patients: results from a retrospective analysis
}

This article was published in the following Dove Press journal:

Integrated Pharmacy Research and Practice

17 February 2017

Number of times this article has been viewed

\author{
Ahsan Saleem ${ }^{1,2}$ \\ Imran Masood' \\ Tahir Mehmood Khan ${ }^{3}$ \\ 'Department of Pharmacy, The Islamia \\ University of Bahawalpur, Bahawalpur, \\ Pakistan; ${ }^{2}$ Pharmacy Services \\ Department, Integrated Medical \\ Center, The Aga Khan University \\ Hospital, Lahore, Pakistan; ${ }^{3}$ School of \\ Pharmacy, Monash University, Sunway \\ Campus, Selangor, Malaysia
}

Background: Chronic kidney disease (CKD) alters the pharmacokinetic and pharmacodynamic responses of various renally excreted drugs and increases the risk of drug-related problems, such as drug-drug interactions.

Objectives: To assess the pattern, determinants, and clinical relevancy of potential drug-drug interactions (pDDIs) in CKD patients.

Materials and methods: This study retrospectively reviewed medical charts of all CKD patients admitted in the nephrology unit of a tertiary care hospital in Pakistan from January 2013 to December 2014. The Micromedex Drug-Reax ${ }^{\circledR}$ system was used to screen patient profiles for pDDIs, and IBM SPSS version 20 was used to carry out statistical analysis.

Results: We evaluated 209 medical charts and found pDDIs in nearly 78.5\% CKD patients. Overall, 541 pDDIs were observed, of which, nearly $60.8 \%$ patients had moderate, $41.1 \%$ had minor, $27.8 \%$ had major, and $13.4 \%$ had contraindicated interactions. Among those interactions, $49.4 \%$ had good evidence, $44.0 \%$ had fair, $6.3 \%$ had excellent evidence, and $35.5 \%$ interactions had delayed onset of action. The potential adverse outcomes of pDDIs included postural hypotension, QT prolongation, ceftriaxone-calcium precipitation, cardiac arrhythmias, and reduction in therapeutic effectiveness. The occurrence of pDDIs was found strongly associated with the age of $<60$ years, number of prescribed medicines $\geq 5$, hypertension, and the lengthy hospitalization of patients.

Conclusion: The occurrence of pDDIs was high in CKD patients. It was observed that CKD patients with an older age, higher number of prescribed medicines, lengthy hospitalization, and hypertension were at a higher risk of pDDIs.

Keywords: potential drug-drug interactions, interactions, CKD, pharmacist, clinical pharmacy, DDI, drug interaction, chronic kidney disease, Pakistan

\section{Introduction}

Chronic kidney disease (CKD) is one of the major challenges that affects $\sim 8 \%-16 \%$ of the population worldwide. ${ }^{1,2}$ If patients with compromised renal function get some secondary complication, then risk assessment becomes essential to avoid any hazardous or damaging effects on the kidneys. ${ }^{3}$ In the case of negligence, the damaging or unwanted effects may appear in the form of adverse drug reactions, idiosyncratic reactions, hypersensitive reactions, or drug-drug interactions (DDIs). "A DDI means a phenomenon by which a drug potentiates or diminishes the effect of other drugs by pharmacokinetics, pharmacodynamics, or various other mechanisms". ${ }^{5}$

Drug-related problems, such as DDIs, are one of the major therapeutic challenges for the treatment of inpatients, especially for those who are suffering from CKD, due
Department of Pharmacy, The Islamia University of Bahawalpur, Railway Road, Bahawalpur, Postal Code 63100, Pakistan Email saleemahsan77@gmail.com 
to its complex nature. ${ }^{6}$ Various studies done in developing countries have revealed that the chances of DDIs are present in $\sim 11.0 \%$ of patients, rising to $40.0 \%$ among patients taking five drugs, and $80.0 \%$ in patients with more than five medicines. ${ }^{7}$ Earlier studies also report that $\sim 74.9 \%$ of CKD patients may have one or more potential DDI (pDDI). ${ }^{8}$

DDI studies are being widely performed worldwide..$^{7,9}$ These studies are being conducted particularly in those clinical settings where the pharmaceutical services departments are well established and clinical pharmacists are efficiently monitoring and making individual patients' therapy safe and cost-effective by making different interventions. ${ }^{7,10,11}$

CKD is highly prevalent in Pakistan when compared with other chronic noncommunicable diseases and affects $\sim 12.5 \%$ $(11.4 \%-13.8 \%)$ of the population. ${ }^{12}$ The majority of Pakistani public sector hospitals are fully funded by the government, and medical care and medicines are provided free-of-charge to both inpatients and outpatients. ${ }^{13}$ However, in spite of these benefits, inappropriate prescribing and occurrence of DDIs remain a big challenge to the health care system in Pakistan. ${ }^{14-16}$ In addition, the majority of public sector hospitals are lacking a well-developed clinical pharmacy setup and, to the best of our knowledge, there is an insufficiency of data on the pattern, determinants, and clinical relevancy of DDIs in CKD patients in Pakistan. Therefore, this study is conducted to assess the pattern, determinants, and clinical relevancy of pDDIs in Pakistani CKD patients.

\section{Materials and methods Study design and setting}

This retrospective study was carried out in a nephrology unit of Bahawal Victoria Hospital (BVH), which is a 1600-bed tertiary care hospital located in Bahawalpur, Punjab, Pakistan. Bahawalpur is a district headquarter with an estimated population of 2,433,091 composed of $52.6 \%$ males and $72.6 \%$ population lives in rural areas. ${ }^{17}$ However, due to a lack of health care facilities in Bahawalpur, BVH is the only tertiary care teaching hospital throughout the district, which serves a huge population and caters for a high patient burden.

\section{Sampling and data collection}

During this study, the medical charts of CKD patients admitted in the nephrology unit of BVH from January 2013 to December 2014 were evaluated. Demographic and clinical data such as the gender, age, length of hospital stay, CKD stage, comorbidity, and the treatment provided were collected.

\section{Assessment of pDDls}

The Micromedex Drug-Reax System (Thomson Reuters Healthcare Inc., Greenwood Village, CO, USA) ${ }^{18}$ was used to evaluate the occurrence of pDDI in CKD patients. Micromedex is a drug-specific pDDIs-detecting software, which possesses sufficient sensitivity ( $\geq 83 \%$ ) and specificity $(\geq 90 \%)$ to detect DDIs. ${ }^{19,20}$ In addition, this software was used to measure the mechanism and potential adverse outcomes of pDDIs. All of the identified pDDIs were classified based on their severity, onset of action, and documented evidence, and tables were generated. These levels are described in the Micromedex Drug-Reax System, ${ }^{18}$ as shown in Box 1.

\section{Statistical analysis}

Descriptive statistics was applied to evaluate patient characteristics. Logistic regression was applied to identify the association between the pDDIs and the patient characteristics. In the model, the exposure to pDDIs was considered dependent variable ( $0=$ absent, $1=$ present $)$. Further variables used in the model as predictors of pDDIs were as follows: gender ( $1=$ female, $2=$ male), age $(1=<60$ years, $2=\geq 60$ years), number of prescribed drugs $(1=<5,2=\geq 5)$, length of hospitalization ( $1=<5$ days, $2=\geq 5$ days), $C K D$ stage $(1=$ stages $1-3,2=$ stages $4-5)$, diabetes $(1=$ Yes, $2=\mathrm{No})$, and hypertension $(1=$ Yes, $2=\mathrm{No}$ ). The Hosmer-Lemeshow test was used to check the goodness-of-fit of the model and a $p$-value of $\leq 0.05$ was

Box I Micromedex adapted classification about the type of onset, severity, and evidence of pDDI

Type of onset
Rapid: effect may occur within 24 hours.
Delayed: the effect may occur after 24 or more hours.
Severity of pDDI
Contraindicated: the drug combination cannot be used concurrently.
Major: more risk of permanent damage or even death and/or
require medical intervention.
Moderate: the interaction may deteriorate patient's condition and
may require alteration of therapy.
Minor: interaction do not impair therapeutic outcome and not
require change in therapy.
Evidence of pDDI
Excellent: the interaction has been clearly demonstrated in well-
controlled studies.
Good: studies strongly suggest that the interaction exists; however,
proof of well-controlled studies is lacking.
Fair: available evidence is poor, but clinicians suspect the interaction
on the basis of pharmacologic considerations or evidence is good
for an interaction of pharmacologically similar drug.
Poor: theoretically, the interaction may occur but reports are very
limited, such as few case reports.
Unlikely: data are very poor and lack a pharmacological basis.
Movion

Abbreviation: pDDI, potential drug-drug interaction. 
considered statistically significant. IBM Statistical Package for the Social Sciences (SPSS) version 20 was used to carry out all statistical analyses.

\section{Ethical approval}

The study was approved by the Pharmacy Research Ethics Committee (PREC) of the Department of Pharmacy, The Islamia University of Bahawalpur, Pakistan. Patient consent to review their medical records could not be obtained due to the lack of patients' contact details at the concerned hospital. To satisfy PREC, approval was obtained from the administration of concerned hospital to access and use the un-anonymized and de-identified data.

\section{Results}

In total, 209 medical charts of CKD patients were evaluated. Of them, the majority (60.8\%) were males. The majority of the patients were aged between 20 and 40 years, and the mean age of the patients was 38.34 years with a standard deviation of \pm 16.82 . About $74.2 \%$ of the patients had CKD stage 5 . More than half of the patients $(65.1 \%)$ had a length of hospitalization $>5$ days. Diabetes and hypertension were present in $18.2 \%$ and $69.9 \%$ patients, respectively, and nearly $78.0 \%$ of the patients were prescribed more than five medicines (Table 1).

In terms of prevalence, nearly $541 \mathrm{pDDIs}$ were observed in $164(78.5 \%)$ CKD patients, of which $60.8 \%$ patients had

Table I Characteristics of chronic kidney disease patients

\begin{tabular}{lll}
\hline Variables & Frequency & Percentage \\
\hline Gender & 127 & \\
Male & 82 & 60.8 \\
Female & & 39.2 \\
Age (years) & 33 & 15.8 \\
$<20$ & 94 & 45.0 \\
$20-40$ & 60 & 28.7 \\
$41-60$ & 22 & 10.5 \\
$>60$ & & \\
Length of hospital stay (days) & 73 & 34.9 \\
$<5$ & 136 & 65.1 \\
$\geq 5$ & & \\
Number of prescribed medicines & 46 & 22.0 \\
$<5$ & 163 & 78.0 \\
$\geq 5$ & & \\
Stage of chronic kidney disease & 1 & 0.5 \\
I & 3 & 1.4 \\
2 & 19 & 9.1 \\
3 & 31 & 14.8 \\
4 & 155 & 74.2 \\
5 & & \\
Comorbidity & 38 & 18.2 \\
Diabetes & 146 & 69.9 \\
Hypertension & &
\end{tabular}

Table 2 Prevalence and levels of potential drug-drug interactions (pDDIs) in chronic kidney disease patients

\begin{tabular}{|c|c|c|c|}
\hline Type of prevalence & Patient, n (\%) & Levels & $\begin{array}{l}\text { Frequency, } \\
\text { n (\%) }\end{array}$ \\
\hline Overall prevalence ${ }^{\mathrm{a}}$ & $164(78.5)$ & Total pDDls & $54 I(100.0)$ \\
\hline Severity of pDDls ${ }^{b}$ & & Severity & \\
\hline Contraindicated & $28(13.4)$ & Contraindicated & $30(5.5)$ \\
\hline Major & $58(27.8)$ & Major & $75(13.9)$ \\
\hline Moderate & $127(60.8)$ & Moderate & $306(56.6)$ \\
\hline Minor & $86(4 I .1)$ & Minor & $130(24.0)$ \\
\hline \multicolumn{2}{|c|}{ Number of pDDls per patient } & Evidence & \\
\hline $1-2$ & $81(38.8)$ & Excellent & $34(6.3)$ \\
\hline $3-5$ & $58(27.8)$ & Good & $267(49.4)$ \\
\hline$\geq 6$ & $25(12.0)$ & Fair & $240(44.3)$ \\
\hline Median & 3 & Onset & \\
\hline Range & $1-22$ & Rapid & $187(34.6)$ \\
\hline \multirow[t]{2}{*}{ Total pDDls } & 541 & Delayed & $192(35.5)$ \\
\hline & & Not specified & $163(29.9)$ \\
\hline
\end{tabular}

Notes: a ${ }^{\circ}$ verall prevalence means the presence of at least one pDDI regardless of severity type; ${ }^{b}$ percentages do not add up to $78.5 \%$ because many patients were exposed to multiple pDDls of different severities.

moderate, $41.1 \%$ had minor, $27.8 \%$ had major, and nearly $13.4 \%$ patients had contraindicated interactions. Nearly 137 different drug interacting combinations were observed. Further analysis revealed that $49.4 \%$ pDDIs had good evidence, $44.3 \%$ had fair evidence, $6.3 \%$ had excellent evidence, and the majority of interaction (35.5\%) had delayed onset of action (Table 2). It was also observed that 306 moderate pDDIs of 541 accounted for $56.2 \%$ of all pDDIs (Table 2).

The pDDIs observed in this study are given in Table 3. The majority of CKD patients were hypertensive; therefore, a separate table was also generated to highlight frequently occurring interactions in hypertensive CKD patients (Table 4). Logistic regression was applied, and predictors of pDDIs with a $p$-value of $<0.1$ in univariate analysis were further evaluated. The multivariate analysis of predictors revealed that gender (odds ratio $[\mathrm{OR}]=1.65 ; 95 \%$ confidence interval $[\mathrm{CI}]=0.9-3.2 ; p=0.136$ ) was not associated with the occurrence of pDDIs. However, a significant association was observed with the age of $<60$ years $(\mathrm{OR}=0.3 ; 95 \% \mathrm{CI}=0.1-$ $0.8 ; p=0.019)$, length of hospital stay $\geq 5$ days $(\mathrm{OR}=2.4$; $95 \% \mathrm{CI}=1.1-5.0 ; p=0.024)$, presence of a comorbidity such as hypertension $(\mathrm{OR}=3.0 ; 95 \% \mathrm{CI}=1.2-7.5 ; p=0.017)$, and number of prescribed drugs $\geq 5$ ( $\mathrm{OR}=6.8 ; 95 \% \mathrm{CI}=3.1-15.1$; $p<0.001)$. The details are shown in Table 5 .

\section{Discussion}

To the best of our knowledge, this was the first study of its kind conducted at a tertiary care public sector hospital in Bahawalpur, which is a comparatively less developed district than others in Punjab province, Pakistan. The consequences 
Table 3 Most frequently occurring major, moderate, and contraindicated interactions, their levels, and potential adverse outcomes

\begin{tabular}{|c|c|c|c|c|c|c|}
\hline Interaction & Frequency & Percentage & Severity & Evidence & Onset & Potential adverse outcomes \\
\hline Ferrous sulfate + omeprazole & 34 & 5.8 & Moderate & Good & Rapid & Reduced non-heme iron bioavailability \\
\hline Calcium/vitamin D + ciprofloxacin & 28 & 4.8 & Moderate & Good & Rapid & Decreased ciprofloxacin efficacy \\
\hline Captopril + furosemide & 24 & 4.1 & Moderate & Good & Rapid & Postural hypotension \\
\hline Calcium gluconate + ceftriaxone & 21 & 3.6 & Contraindicated & Good & Not specified & $\begin{array}{l}\text { Formation of ceftriaxone-calcium } \\
\text { precipitates }\end{array}$ \\
\hline Ciprofloxacin + ferrous sulfate & 17 & 2.9 & Moderate & Fair & Rapid & Decreased ciprofloxacin effectiveness \\
\hline Amlodipine + atenolol & 13 & 2.2 & Moderate & Good & Rapid & Hypotension and/or bradycardia \\
\hline Amlodipine + ciprofloxacin & 12 & 2.0 & Moderate & Fair & Not specified & Increased amlodipine exposure \\
\hline Amlodipine + prednisolone & 11 & 1.9 & Moderate & Fair & Not specified & Reduced amlodipine efficacy \\
\hline Furosemide + lisinopril & 11 & 1.9 & Moderate & Good & Rapid & Postural hypotension \\
\hline Atenolol + prazosin & 10 & 1.7 & Moderate & Good & Rapid & Exaggerated hypotensive response \\
\hline Ciprofloxacin + metronidazole & 9 & 1.5 & Major & Fair & Not specified & $\begin{array}{l}\text { Increased risk of QT-interval } \\
\text { prolongation and arrhythmias }\end{array}$ \\
\hline Aspirin + calcium/vitamin D & 8 & $\mathrm{I} .4$ & Moderate & Fair & Delayed & Decreased salicylate effectiveness \\
\hline Ciprofloxacin + prednisolone & 8 & $\mathrm{I} .4$ & Moderate & Excellent & Delayed & Increased risk of tendon rupture \\
\hline Amlodipine + carbamazepine & 6 & 1.0 & Major & Fair & Not specified & Decreased exposure of amlodipine \\
\hline Amlodipine + aspirin & 6 & 1.0 & Moderate & Good & Delayed & $\begin{array}{l}\text { Increased risk of gastrointestinal } \\
\text { hemorrhage and/or antagonism of } \\
\text { hypotensive effect }\end{array}$ \\
\hline Aspirin + sodium bicarbonate & 6 & 1.0 & Moderate & Fair & Delayed & Decreased salicylate effectiveness \\
\hline Metronidazole + moxifloxacin & 5 & 0.9 & Major & Fair & Not specified & $\begin{array}{l}\text { Increased risk of QT-interval } \\
\text { prolongation and arrhythmias }\end{array}$ \\
\hline Aspirin + insulin human regular & 5 & 0.9 & Moderate & Fair & Not specified & Increased risk of hypoglycemia \\
\hline Carbamazepine + omeprazole & 5 & 0.9 & Moderate & Good & Delayed & $\begin{array}{l}\text { Increased risk of carbamazepine } \\
\text { toxicity }\end{array}$ \\
\hline Enalapril + furosemide & 5 & 0.9 & Moderate & Good & Rapid & Postural hypotension \\
\hline Amlodipine + simvastatin & 4 & 0.7 & Major & Good & Rapid & $\begin{array}{l}\text { Increased simvastatin exposure and } \\
\text { increased risk of myopathy, including } \\
\text { rhabdomyolysis }\end{array}$ \\
\hline Lisinopril + spironolactone & 4 & 0.7 & Major & Good & Delayed & Hyperkalemia \\
\hline Atorvastatin + clopidogrel & 4 & 0.7 & Moderate & Excellent & Not specified & High on-treatment platelet reactivity \\
\hline Carbamazepine + ciprofloxacin & 4 & 0.7 & Moderate & Fair & Not specified & Increased carbamazepine exposure \\
\hline Ferrous sulfate + moxifloxacin & 4 & 0.7 & Moderate & Good & Rapid & Decreased moxifloxacin effectiveness \\
\hline Furosemide + insulin human regular & 4 & 0.7 & Moderate & Fair & Not specified & $\begin{array}{l}\text { Increased hyperglycemia risk; } \\
\text { increased insulin requirement }\end{array}$ \\
\hline Calcium acetate + ceftriaxone & 3 & 0.5 & Contraindicated & Good & Not specified & $\begin{array}{l}\text { Formation of ceftriaxone-calcium } \\
\text { precipitates }\end{array}$ \\
\hline
\end{tabular}

of drug-related problems, such as, DDIs, can potentially complicate the nature and severity of an illness such as CKD that itself requires multiple and complex therapeutic regimens. ${ }^{21,22}$ To ensure rational prescribing in high-risk patients, it is necessary to evaluate and identify the factors causing DDIs before any adverse outcome occurs.

The incidence of pDDIs identified in this study is $78.5 \%$. This incidence is much higher than a Malaysian study in which a sample of 308 patients was taken, of which only 154 patients had confirmed CKD diagnosis and the reported incidence of pDDIs was $19.4 \%$. The lower pDDI rate in a Malaysian study could be due to their lower sample size. ${ }^{23}$ Marquito et $\mathrm{al}^{8}$ reported $74.9 \%$ pDDIs prevalence in Brazilian CKD patients, of which $\sim 54.7 \%$ were males and the majority were aged $\sim 70$ years. Similarly, the prevalence of $\mathrm{pDDI}$ was reported as $76.1 \%$ in an Indian study. ${ }^{24}$ Hence, although variations exists in study designs of previous studies, a high prevalence of pDDIs has been observed in CKD patients, which supports our study findings.

Earlier studies reported a high incidence of pDDI in Pakistan, especially in pediatric patients, ${ }^{25}$ internal medicine ward patients, ${ }^{26}$ psychiatry patients, ${ }^{9}$ and cardiac patients. ${ }^{27}$ The cumulative findings of these studies suggest that the prevalence of pDDIs may range from $25.8 \%$ to $91.1 \%$ in Pakistan., ${ }^{9,25,27}$ The published literature suggests that CKD mainly affects the older population, that is, at high risk of adverse drug effects due to multiple comorbidities such as diabetes and hypertension, and especially when they are prescribed multiple therapies or even a single drug, due to various pharmacokinetic reasons. ${ }^{28}$ 
Table 4 Most commonly occurring drug interactions in hypertensive chronic kidney disease patients

\begin{tabular}{lll}
\hline Interacting pair & Frequency & Percentage \\
\hline Ferrous sulfate + omeprazole & 27 & 5.8 \\
Calcium/vitamin D + ciprofloxacin & 21 & 4.5 \\
Captopril + furosemide & 21 & 4.5 \\
Calcium gluconate + ceftriaxone sodium & 16 & 3.4 \\
Calcium gluconate + ferrous sulfate & 14 & 3.0 \\
Ciprofloxacin + ferrous sulfate & 14 & 3.0 \\
Amlodipine + atenolol & 13 & 2.8 \\
Atenolol + prazosin & 10 & 2.2 \\
Amlodipine + prednisolone & 9 & 1.9 \\
Amlodipine + ciprofloxacin & 8 & 1.7 \\
Aspirin + calcium/vitamin D & 8 & 1.7 \\
Ciprofloxacin + metronidazole & 7 & 1.5 \\
Furosemide + lisinopril & 7 & 1.5 \\
Amlodipine + aspirin & 6 & 1.3 \\
Amlodipine + carbamazepine & 6 & 1.3 \\
Aspirin + sodium bicarbonate & 6 & 1.3 \\
Aspirin + insulin human regular & 5 & 1.1 \\
Ciprofloxacin + prednisolone & 5 & 1.1 \\
Amlodipine + simvastatin & 4 & 0.9 \\
Atorvastatin + clopidogrel & 4 & 0.9 \\
Carbamazepine + ciprofloxacin & 4 & 0.9 \\
Carbamazepine + omeprazole & 4 & 0.9 \\
\hline Notes The freq & &
\end{tabular}

Notes: The frequency and percentage depicted in the table is based on total 465 interactions that were observed in hypertensive chronic kidney disease patients.
This study showed that $\sim 60.8 \%$ of pDDIs were moderate and $41.1 \%$ were minor. These are higher than an Indian study, which reported $57.0 \%$ moderate pDDIs and only $23.2 \%$ minor pDDIs. ${ }^{24}$ The relatively high incidence of pDDIs in a Pakistani hospital is perhaps due to some potential barriers, such as the unavailability of clinical pharmacy staff, lack of multidisciplinary teams, lack of patient centeredness, shortage of time and overburden on physicians, and may be poor knowledge of the medical staff to identify pDDIs in usual clinical practice. ${ }^{29}$

The majority of the pDDIs identified in this study are of moderate and minor severity. A few interactions with serious and contraindicated severity have also been observed, which have considerable potential to deteriorate patients' clinical condition, if left unmanaged (Tables 2 and 3 ). We observed that the pDDIs identified in this study are not specific only to CKD patients. Some interactions, such as furosemide + lisinopril, captopril + furosemide, and aspirin + insulin, have also been observed in internal medicine ward patients who were suffering from stroke, pyrexia, gastroenteritis, congestive heart failure, malaria, anemia, tuberculosis, ischemic heart disease, liver cirrhosis, pneumonia, meningitis, and urinary tract infection. ${ }^{26}$

Table 5 Predictors of potential drug-drug interactions in chronic kidney disease (CKD) patients

\begin{tabular}{|c|c|c|c|c|c|c|}
\hline \multirow[t]{2}{*}{ Variables } & \multicolumn{2}{|c|}{ Patients $(n=209)$} & \multicolumn{2}{|l|}{ Univariate } & \multicolumn{2}{|l|}{ Multivariate } \\
\hline & $\begin{array}{l}\text { Interaction } \\
\text { present, n (\%) }\end{array}$ & $\begin{array}{l}\text { Interaction absent, } \\
\text { n (\%) }\end{array}$ & OR (95\% Cl) & $p$-Value & OR $(95 \% \mathrm{Cl})$ & $p$-Value \\
\hline \multicolumn{7}{|l|}{ Gender } \\
\hline Male & $104(81.9)$ & $23(18.1)$ & $1.65(0.9-3.2)$ & 0.136 & - & - \\
\hline Female & $60(73.2)$ & $22(26.8)$ & & & & \\
\hline \multicolumn{7}{|c|}{ Age (years) } \\
\hline$<60$ & $150(80.2)$ & $37(19.8)$ & $0.4(0.2-0.9)$ & 0.012 & $0.3(0.1-0.8)$ & 0.019 \\
\hline$\geq 60$ & $14(63.6)$ & $8(36.4)$ & & & & \\
\hline \multicolumn{7}{|c|}{ Hospital stay (days) } \\
\hline$<5$ & $48(65.8)$ & $25(34.2)$ & $3.0(1.5-5.9)$ & 0.001 & $2.4(I . I-5.0)$ & 0.024 \\
\hline$\geq 5$ & $116(85.3)$ & $20(14.7)$ & & & & \\
\hline \multicolumn{7}{|c|}{ Number of drugs } \\
\hline$<5$ & $23(50.0)$ & $23(50.0)$ & $6.4(3.1-13.3)$ & $<0.001$ & $6.8(3.1-15.1)$ & $<0.001$ \\
\hline$\geq 5$ & $|4|(86.5)$ & $22(13.5)$ & & & & \\
\hline \multicolumn{7}{|l|}{ CKD stage } \\
\hline $\mathrm{I}-3$ & $15(65.2)$ & $8(34.8)$ & $0.5(0.2-1.2)$ & 0.107 & - & - \\
\hline $4-5$ & $149(8 \mid .0)$ & $37(19.9)$ & & & & \\
\hline \multicolumn{7}{|l|}{ Diabetes } \\
\hline Yes & $33(86.8)$ & $5(13.2)$ & $2.0(0.7-5.5)$ & 0.172 & - & - \\
\hline No & $|3|(76.6)$ & $40(23.4)$ & & & & \\
\hline \multicolumn{7}{|c|}{ Hypertension } \\
\hline Yes & $12 \mid$ (82.9) & $25(17.1)$ & $2.3(1.1-4.5)$ & 0.020 & $3.0(1.2-7.5)$ & 0.017 \\
\hline No & $43(68.3)$ & $20(31.7)$ & & & & \\
\hline
\end{tabular}

Notes: Hosmer-Lemeshow goodness-of-fit test: $p=0.65$. Data in bold indicates statistical significance $(P$-value $<0.05)$ obtained after statistical analysis.

Abbreviations: $\mathrm{OR}$, odds ratio; $\mathrm{Cl}$, confidence interval. 
We suggest that the consequences of pDDIs should be considered carefully because some interactions that appear in the pDDI checking software do not occur in usual practice, that is, calcium gluconate + ceftriaxone interaction takes places only in the infusion bag, if mixed together. But if given separately (oral calcium and IM/IV ceftriaxone), then there is no need to worry. ${ }^{30}$ Therefore, it should be kept in mind that the various drug-screening software including Drug-Reax System provide only an instant computerized drug interaction contents, which should be assessed carefully by the clinical pharmacists. To understand pDDIs carefully, physicians should consult pharmacists while prescribing drugs to CKD patients and seek their expertise to avoid over or underestimation of the clinical relevancy of pDDIs.

Finally, the findings such as the associations of pDDIs with the lengthy hospitalization, higher number of medicines prescribed, and the un-association of pDDIs with the gender are in line with previous studies. ${ }^{26,27}$ However, to the best of our knowledge, the findings such as the association of pDDIs with an age of $<60$ years and hypertension were not reported before. We also tried to study the impact of CKD stage and diabetes on the occurrence of pDDI, but the multivariate analysis confirmed that there was no such association. Further research can be conducted to answer this question using a large and multicenter data. Moreover, research should be done to identify various other factors, such as the use of a particular drug class, multiple prescribers, disease diagnosis, and the type and number of comorbid illnesses.

\section{Conclusion}

The prevalence of pDDIs is high in CKD patients in Pakistan. The determinants of pDDIs are the age of $<60$ years, length of hospital stay $\geq 5$ days, presence of hypertension, and the number of prescribed medications $\geq 5$. The higher occurrence of pDDIs in our study setting reflects the lack of knowledge in prescribers about detecting pDDIs and indicates the importance of clinical pharmacy staff that can help in managing and reducing pDDIs in CKD patients. To make pDDIs screening more effective, both clinical pharmacists and physicians are advised to work in a more collaborative manner.

\section{Clinical implications and recommendations}

The DDIs are a major challenge to the effective management of hospitalized CKD patients. The majority of the pDDIs identified in this study are of moderate and minor severity and lack of clinical relevancy which reflects that nephrologists are prescribing somewhat rationally. However, a few severe and contraindicated interactions have also been observed that have a considerable potential to deteriorate patients' clinical condition, if left unmanaged. The occurrence of major and contraindicated interactions in CKD patients indicates the need of clinical pharmacy staff at nephrology units of hospitals. In terms of practice, except for the major pDDIs, the moderate and severe DDIs are usually not considered. To make prescribing safer, careful understanding about pDDIs even for a minor or moderate severity is important. In addition, as this study showed that CKD patients who are in the age of $<60$ years, experience a lengthy hospital stay, have hypertension, and are on multiple therapies are at more risk of pDDIs. Therefore, physicians and pharmacists should take care of patients who fall under these categories. We advise pharmacists to play their role wisely in Pakistani tertiary level hospitals in a more collaborative way to reduce work burden on physicians and ensure the quality use of medicines.

\section{Study limitations}

The potential limitations of this study are as follows: first, the actual adverse effects or outcomes of the identified pDDIs could not be studied due to the lack of stored data in the hospital concerned. Therefore, further studies should be conducted to evaluate the actual and clinical consequences of pDDIs in CKD patients. Second, due to a lack of funding, this study was carried out in only one public sector tertiary care teaching hospital; therefore, these study findings should be carefully generalized across the Pakistan.

\section{Acknowledgments}

This research work was carried out at The Islamia University of Bahawalpur, Pakistan. The views presented in the article are authors' own and the primary author's second and most recent affiliation "The Aga Khan University Hospital" has no role in the conceptualization or publication of research work. The authors are very grateful to the administration, consultants, and all other staff of Bahawal Victoria Hospital for providing administrative support, and Mr. Abdul Wahab Khan and Mr. Saqib Sohaib Mahmood, students at The Islamia University of Bahawalpur, Pakistan, for helping in data collection. In addition, we would like to acknowledge Richard from Amsterdam for proof reading our article for language appropriateness.

\section{Disclosure}

The authors report no conflicts of interest in this work.

\section{References}

1. Abegunde DO, Mathers CD, Adam T, Ortegon M, Strong K. The burden and costs of chronic diseases in low-income and middle-income countries. Lancet. 2007;370(9603):1929-1938. 
2. Arora P, Vasa P, Brenner D, et al. Prevalence estimates of chronic kidney disease in Canada: results of a nationally representative survey. CMAJ. 2013;185(9):E417-E427.

3. Arellano J, Hernandez RK, Wade SW, et al. Prevalence of renal impairment and use of nephrotoxic agents among patients with bone metastases from solid tumors in the United States. Cancer Med. 2015;4(5):713-720.

4. Krähenbühl-Melcher A, Schlienger R, Lampert ML, Haschke M, Drewe J, Krahenbuhl S. Drug-related problems in hospitals: a review of the recent literature. Drug Saf. 2007;30(5):379-407.

5. Baxter K, Preston CL. Stockley's Drug Interactions. 10th ed. London, UK: Pharmaceutical Press; 2013.

6. Nickel CH, Ruedinger JM, Messmer AS, et al. Drug-related emergency department visits by elderly patients presenting with non-specific complaints. Scand J Trauma Resusc Emerg Med. 2013;21(15):1-9.

7. Bhagavathula AS, Berhanie A, Tigistu H, et al. Prevalence of potential drug-drug interactions among internal medicine ward in University of Gondar Teaching Hospital, Ethiopia. Asian Pac J Trop Biomed. 2014; 4(Suppl 1):S204-S208.

8. Marquito AB, Fernandes NM, Colugnati FA, de Paula RB. Interações medicamentosas potenciais em pacientes com doença renal crônica. [Identifying potential drug interactions in chronic kidney disease patients]. J Bras Nefrol. 2014;36(1):26-34. Portuguese.

9. Ismail M, Iqbal Z, Khattak MB, et al. Potential drug-drug interactions in psychiatric ward of a tertiary care hospital: prevalence, levels and association with risk factors. Trop J Pharma Res. 2012;11(2):289-296.

10. Kjeldsen LJ, Birkholm T, Fischer H, et al. Characterization of drugrelated problems identified by clinical pharmacy staff at Danish hospitals. Int J Clin Pharm. 2014;36(4):734-741.

11. Jiang SP, Chen J, Zhang XG, Lu XY, Zhao QW. Implementation of pharmacists' interventions and assessment of medication errors in an intensive care unit of a Chinese tertiary hospital. Ther Clin Risk Manag. 2014;10:861-866.

12. Jessani S, Bux R, Jafar TH. Prevalence, determinants, and management of chronic kidney disease in Karachi, Pakistan - a community based cross-sectional study. BMC Nephrol. 2014;15:90.

13. Naz A, Daraz U, Khan T, Khan W, Hussain M. An analytical study of patients' health problems in public hospitals of Khyber Pakhtunkhwa Pakistan. Int J Business Social Sci. 2012;3(5):133-143.

14. Khan TM. Challenges to pharmacy and pharmacy practice in Pakistan. Aust Med J. 2011;4(4):230-235.

15. Khan MU, Ahmad A. The impact of clinical pharmacists' interventions on drug related problems in a teaching based hospital. Int J Pharma Clin Res. 2014;6(3):276-280.
16. Saleem A, Masood I. Pattern and predictors of medication dosing errors in chronic kidney disease patients in Pakistan: a single center retrospective analysis. PLoS One. 2016;11(7):e0158677.

17. Pakistan Bureau of Statistics. District at a glance Bahawalpur. Available from: http://www.pbs.gov.pk/sites/default/files//tables/District\%20 at\%20a\%20glance\%20Bahawalpur.pdf. Accessed December 1, 2016.

18. DRUG-REAX ${ }^{\circledR}$ System (electronic version). Available from: http:// www.micromedexsolutions.com/. Accessed August 20, 2015.

19. Guastaldi RBF, Reis AMM, Figueras A, Secoli SR. Prevalence of potential drug-drug interactions in bone marrow transplant patients. Int J Clin Pharm. 2011;33:1002-1009.

20. Reis A, Cassiani S. Evaluation of three brands of drug interaction software for use in intensive care units. Pharm World Sci. 2010;32(6): 822-828.

21. Hassan Y, Al-Ramahi RJ, Aziz NA, Ghazali R. Drug use and dosing in chronic kidney disease. Ann Acad Med Singapore. 2009;38(12): 1095-1103.

22. Kappel J, Calissi P. Nephrology: 3. Safe drug prescribing for patients with renal insufficiency. CMAJ. 2002;166(4):473-477.

23. Mahmoud MA. Drug Therapy Problems and Quality of Life in Patients With Chronic Kidney disease [master's thesis]. Malaysia: School of Pharmacy, Universiti Sains Malaysia; 2008.

24. Rama M, Viswanathan G, Acharya LD, Attur RP, Reddy PN, Raghavan SV. Assessment of drug-drug interactions among renal failure patients of nephrology ward in a south Indian tertiary care hospital. Indian $J$ Pharma Sci. 2012;74(1):63-68.

25. Ismail M, Iqbal Z, Khan MI, et al. Frequency, levels and predictors of potential drug-drug interactions in a pediatrics ward of a teaching hospital in Pakistan. Trop J Pharma Res. 2013;12(3):401-406.

26. Ismail M, Iqbal Z, Khattak MB, et al. Potential drug-drug interactions in internal medicine wards in hospital setting in Pakistan. Int J Clin Pharm. 2013;35:455-462.

27. Murtaza G, Khan MYG, Azhar S, Khan SA, Khan TM. Assessment of potential drug-drug interactions and its associated factors in the hospitalized cardiac patients. Saudi Pharma J. 2016;24(2):220-225.

28. Gallieni M, Cancarini G. Drugs in the elderly with chronic kidney disease. Nephrol Dial Transplant. 2015;30(3):342-344.

29. Nazar CMJ, Kindratt TB, Ahmad SMA, Ahmed M, Anderson J. Barriers to the successful practice of chronic kidney diseases at the primary health care level; a systematic review. J Ren Inj Prev. 2014;3(3):61-67.

30. Steadman E, Raisch DW, Bennett CL, et al. Evaluation of a potential clinical interaction between ceftriaxone and calcium. Antimicrob Agents Chemother. 2010;54(4):1534-1540.
Integrated Pharmacy Research and Practice

\section{Publish your work in this journal}

Integrated Pharmacy Research and Practice is an international, peer-reviewed, open access, online journal, publishing original research, reports, reviews and commentaries on all areas of academic and professional pharmacy practice. This journal aims to represent the academic output of pharmacists and pharmacy practice with particular focus on integrated care. All papers are carefully

\section{Dovepress}

peer reviewed to ensure the highest standards as well as ensuring that we are informing and stimulating pharmaceutical professionals. The manuscript management system is completely online and includes a very quick and fair peer-review system, which is all easy to use. Visit http://www.dovepress.com/ testimonials.php to read real quotes from published authors. 